\title{
Solar Powered Electrolysis System for Cooking Applications
}

\author{
Evangelia Topriska $^{a, *}$, Maria Kolokotroni ${ }^{b}$, Zahir Dehouche $^{b}$, and Earle Wilson ${ }^{c}$ \\ ${ }^{a}$ Heriot Watt University Dubai Campus, Dubai, United Arab Emirates \\ ${ }^{b}$ Brunel University, Uxbridge, United Kingdom \\ ${ }^{c}$ University of Technology, Kingston, Jamaica
}

\begin{abstract}
This paper presents a numerical model for a solar powered Proton Exchange Membrane Electrolyser (PEM) for the generation of hydrogen as fuel for cooking applications. The model was developed in TRNSYS software and includes a novel FORTRAN numerical component to model the operation of the PEM electrolyser, based on operational data from a small-scale experimental rig. The numerical model was calibrated using data from the experimental rig powered by operational data from a photovoltaic panel system in the UK and from Jamaica. The calibrated model was used to develop a case study for a small community in Jamaica with a daily cooking demand of $39.6 \mathrm{kWh}$ or $1.68 \mathrm{~kg}$ of H2 gas. Simulation results indicate that the $\mathrm{H} 2$ production strategy is satisfactory for the cooking needs of the case-study and appropriate according to the environmental considerations related to cooking
\end{abstract}

Keywords: Solar Hydrogen, Electrolysis, Photovoltaics, Integrated Renewable Energy, Cooking

\section{Introduction}

Over 2.5 billion people depend on firewood, charcoal, agricultural and animal waste to satisfy their energy needs for cooking. Almost 1.3 million people die prematurely every year because of exposure to indoor air pollution from biomass (IEA, 2006). Poor ventilation and outdated cooking methods result to numerous deaths immediately relating to cooking. Subsequently, many developing countries have turned to the use of petroleum based fuels, as well as charcoal and firewood as their main energy source for cooking (Johnson, 2012). In 2002, cooking with solid fuels was responsible for nearly 800,000 deaths among children and more than 500,000 deaths among women (World Health Organisation, 2006). An additional consequence of using fuelwood and charcoal for cooking is deforestation, which can lead to degradation of the local environment in developing countries. A cost-effective analysis of the World Health Organisation has furthermore indicated that it is worth investing in improving the cooking methods in developing countries (World Health Organisation, 2006). In regions with high solar irradiance one solution would be to use hydrogen as cooking gas produced through photovoltaic powered electrolysis. Electrolytic hydrogen can be used in renewable energy systems for mobile and stationary applications
(Lymperopoulos \& Zoulias, 2008). Proton Exchange Membrane electrolysis especially has been broadly used in integrated renewable energy systems (Zini \& Tartarini, 2012; Barbir, 2005; Bilgen, 2001). Producing electrolytic hydrogen with solar energy as a primary source is a sustainable and environmentally friendly process (Nowotny \& Veziroglou, 2011; Acar \& Dincer, 2013). Hydrogen as an energy carrier medium is a promising option that can replace fossil fuels and inefficient electricity systems (Veziroglou \& Sahin, 2008).

However, the application of a solar powered electrolyser to produce hydrogen as a cooking fuel has not been reported in the literature. The use of hydrogen as a cooking fuel presents future potential and can act as an ameliorating factor for the living conditions of people, especially those in developing countries (UN, 2006; World Health Organisation, 2006). This paper presents the development and case study application of a numerical model of a system that can generate solar powered electrolytic hydrogen as alternative domestic cooking gas and can be used for application in various locations.

\footnotetext{
${ }^{*}$ Corresponding author

E-mail: e.topriska@hw.ac.uk

(C) 2016 International Association for Sharing Knowledge and Sustainability DOI: 10.5383/ijtee.12.02.007
} 


\section{Numerical Model}

The model that simulates the operation of a solar powered PEM electrolyser system was developed in this study using TRNSYS (The University of Wisconsin, 2013). Laboratory experimental measurements are conducted based on the setup of Figure 1 and electrochemical models are also used (Topriska, et al.,

2015). The basic components of the system that are developed in FORTRAN are the PEM electrolyser, the controls and gas management and the metal hydride storage components.

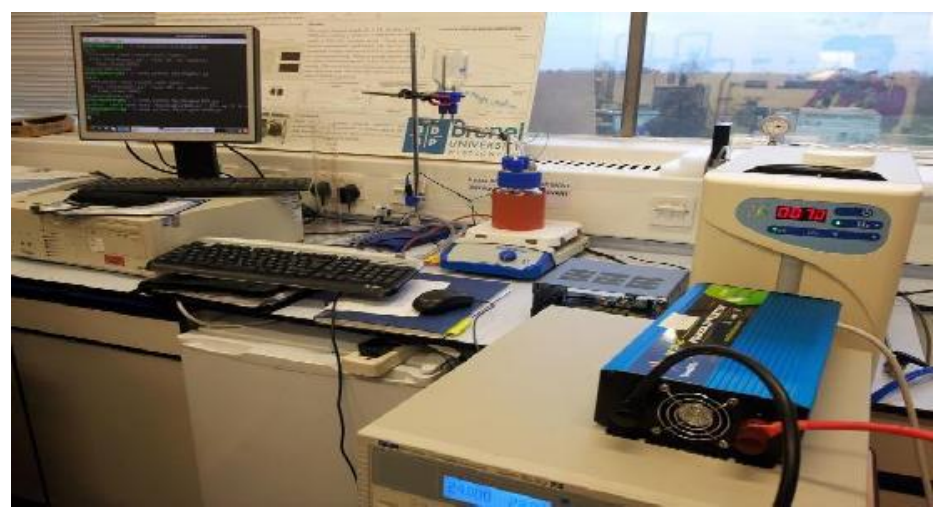

Figure 1, Experimental Setup of the PEM Electrolyser

\subsection{Proton Exchange Membrane Electrolyser}

The PEM electrolyser used in this study is a 4-cell stack unit, by Proton Onsite (Proton Onsite, 2014). It is rated at $1.2 \mathrm{~kW}$ and maximum hydrogen generation at $600 \mathrm{cc} / \mathrm{min}$, with a permissible current of 0-30A, at stack voltage of 6.5-7.5VDC. The PEM electrolyser used operates for hydrogen production pressures in the range of 3 to 13.8 bar. The generation rates depend on the set pressure and the stack generates at the adequate rate so as to achieve the necessary pressure at the outlet. Furthermore, the energy use is also different at each pressure set point. Experiments were conducted and the hydrogen production flow rates, the energy use and temperature of the stack were recorded for pressures between 5 to 13.8 bar with a 1 bar step. The pressure at the output was kept constant for each test with back pressure regulation. The hydrogen generation curve that is developed through polynomial interpolation of the experimental data is given by Equation (1) (Topriska, et al., 2015).

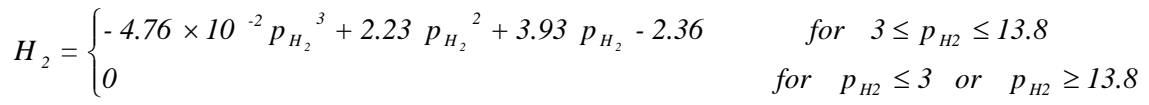

Where $H_{2}$ is the generated hydrogen flow rates in $\mathrm{ml} / \mathrm{min}$ and $p_{H 2}$ the pressure of the generated hydrogen in bar.

\subsection{Electrolyser Controls}

A palladium purification system that includes a heating element operating at $278^{\circ} \mathrm{C}$, a water pump and the electric controls, add extra energy requirements of the electrolyser. An empirical model based on the experimental results of the energy use of the electrolyser is developed and integrated in the controls aspect of the model. The heater works during the start-up of the electrolyser and at certain points during operation that are dependent on the amount of generated hydrogen. When the heater is operating $474 \mathrm{~W}$ extra are added to the electrolyser energy demands. By introducing controls as a combination of the purifier and electrolyser operation, the model offers the possibility to examine different solutions for the operation of the hydrogen purification system. 2.3 Metal Hydride Storage Component.

The storage tank used in this study is a metal hydride storage and the metal hydride alloy employed is $\mathrm{LaNi}_{5}$ and $50 \mathrm{gr}$ are contained in the tank. Based on this storage tank, a numerical component was developed that models the absorption process and is used as a suggested storage method for the case study application. The absorbed mass and charging time are described by the basic Equations (2) and (3):

$$
\begin{aligned}
& H_{2 \text { stored }}=\int_{0}^{\text {Ch arg }} \int_{\text {ingTime }} \text { Flow }\left(\frac{\mathrm{kg}}{\mathrm{min}}\right) d t \\
& \text { Ch arg ingTime }=\frac{H_{2 \mathrm{Max}}}{\text { Flow }\left(\frac{\mathrm{Nm}}{\mathrm{min}}\right)}=\frac{150\left(\frac{\mathrm{ml}}{\mathrm{gr}}\right) * 50 \mathrm{gr} * 10^{-6}\left(\frac{\mathrm{Nm}^{3}}{\mathrm{ml}}\right)}{\text { Flow }\left(\frac{\mathrm{Nm}}{\mathrm{min}}\right)}=\frac{7.5 * 10^{-3} \mathrm{Nm}^{3}}{\text { Flow }\left(\frac{\mathrm{Nm}^{3}}{\mathrm{~min}}\right)}
\end{aligned}
$$




\subsection{Photovoltaic System}

The photovoltaic panels were simulated using standard TRNSYS components for mono-crystalline panels (TRNSYS 17, 2012). The panel's current and voltage relation depends on insolation and temperature and is calculated by Equation (4).

$$
I=I_{L}-I_{o}\left[\exp \left(\frac{V+I \times R_{s}}{\alpha}\right)-1\right]-\frac{V+I \times R_{s}}{R_{s h}}
$$

Where, $\alpha=\frac{N_{s} \times n_{I} \times k \times T_{c}}{q}$

The panels are connected to the electrolyser through an inverter that supplies 230VAC. The losses of the system are computed and the inverter efficiency varies between $86 \%$ to $93 \%$, depending on the fraction of power that goes through, and the AC power.

\section{Validation of TRNSYS Model}

A second experimental study of the system was conducted to validate the developed numerical model. The experiments had a focus on assessing the operation of the electrolyser and the balance-of-plant when it is coupled to a PV system. Two sets of laboratory tests were performed, one for the operation of the electrolyser under weather conditions of the United Kingdom, and one for Jamaica. The operation of the PV panels in the laboratory was emulated through a $1200 \mathrm{~W}$ programmable DC power supply unit coupled with a $24 \mathrm{VDC} / 230 \mathrm{VAC}$ pure sine output power inverter. Python programming was used and a code was developed to control the DC Power Supply Unit. Digital control signals that correspond to current values in amperes are sent from a Raspberry Pi computer through a 12bit digital to analogue converter. This setup provides an automated operation and offers the flexibility to test for different sets of irradiances in the laboratory. For the tests, the DC power supply unit is set at $24 \mathrm{~V}$ constant to match the inverter specifications and the current changes accordingly so that the unit operates as the PV array and the data sent from the Raspberry Pi correspond to current values in Amperes. Comparison between the results of the UK and Jamaica experimental sets and the simulation results is performed and the average difference was $6.22 \%$ for 5 bar and $3.70 \%$ for 13.8bar. The similarity between the experimental and simulation results increases at higher operating pressures.

\section{Simulation Results: A Case Study Application in Jamaica}

A case study has been developed, for 20 households in a Jamaican community. From data mining, the cooking demand for a typical Jamaican household was estimated as $1.98 \mathrm{kWh} /$ day, (The Planning Institute of Jamaica \& The Statistical Institute of Jamaica, 2007). With hydrogen stove efficiency of $60 \%$, this is equivalent to $3.3 \mathrm{kWh} /$ day of hydrogen or $0.0842 \mathrm{~kg}$ of hydrogen per day. Therefore, for the 20 households $1.68 \mathrm{~kg}$ of hydrogen per day is necessary. The TRNSYS model of the Jamaica case study is shown in Figure 2 .

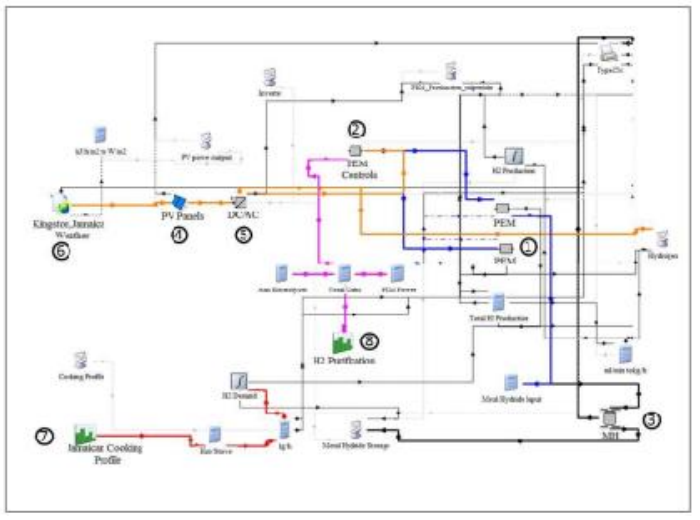

Figure 2, PV Array (4) that Supplies the PEM Electrolyser (1) Through an Inverter (5), The Electrolyser Auxiliary Components (Controls (2), and Gas Management Parts (8)), and the Metal Hydride Storage Components (3). It Also Includes the Necessary Weather Data (6) for the Simulation, the Cooking Load Profile for the Application (7) and Other Computational Components. The Electrolyser is Supplied Through the PV, According to their Yield Which Depends on the Weather Data

Two electrolysers are selected, based on the developed PEM numerical model. The parameters of each one are shown in Table 1 .

Table 1, Each PEM Electrolysers' Parameters in the Ghana Case Study

\begin{tabular}{|c|c|}
\hline Maximum Hydrogen Production rate $\left(\mathrm{Nm}^{3} / \mathrm{h}\right)$ & 2 \\
\hline Stack current $(\mathrm{A})$ & 110 \\
\hline Maximum Stack Power $(\mathrm{kW})$ & 10.25 \\
\hline Hydrogen generation pressure (bar) & 13.8 \\
\hline Stack efficiency & $63.6 \%$ \\
\hline
\end{tabular}

\section{Case Study Simulation Results}

In order to ensure that the photovoltaic array output will be enough to satisfy the demand after 20 years the array is oversized by $6.96 \%$ of the current size that satisfies the demand. Therefore, a $63 \mathrm{~kW}$ array is examined for the Jamaica case study, which after 20 years will reach the level of $58.9 \mathrm{~kW}$ and will still be enough to satisfy the annual cooking needs. The total cooking demand in one year is $622.05 \mathrm{~kg}$ and the 
designed system provides with $653 \mathrm{~kg}$ of hydrogen at current conditions, and $620 \mathrm{~kg}$ of hydrogen after the 20 year period. The production, of the preceding month has to satisfy the demand of the following month, as the purpose is to supply the consumers on a monthly basis. Figure 3 shows the monthly hydrogen demand and equivalent production in $\mathrm{kg}$ for the current conditions and after the 20 year period.

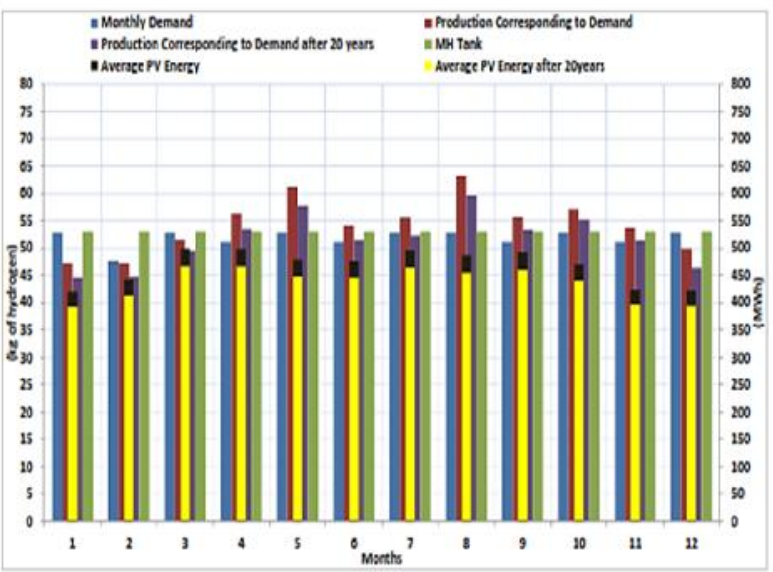

Figure 3, Monthly Demand and Production of Hydrogen and PV Yield for the Current Conditions and After the Panel Degradation Period for the Jamaica Case Study

\section{Conclusions}

This paper examined the application of a solar powered PEM electrolyser system to produce hydrogen at a large scale as a domestic cooking fuel in developing countries. A numerical model of the system in TRNSYS that models the operation of the PEM electrolyser was presented and based on that, a large scale case study analysis was performed for a small community in Jamaica. The annual cooking demand of the community was satisfied by a $63 \mathrm{~kW}$ array and a $2 \mathrm{Nm} 3 /$ hydrogen generation system. The suggested system has significant capital cost but minor operational costs. Moreover, the life span of the system is longer than 20 years and the related emissions come only from the embedded emissions of the materials. Therefore, a government funded solar hydrogen plant is a viable way that can provide free or very low price cooking fuel to developing country communities and replace the currently used cooking fuels (firewood, charcoal and LPG) that are related to health problems and high emissions.

\section{Acknowledgments}

This project is partly funded by ACP Caribbean \& Pacific Research Programme for Sustainable Development of the European Union (EuropeAid/130381/D/ACT/ACP).

\section{References}

[1] The Planning Institute of Jamaica \& The Statistical Institute of Jamaica, 2007. Residential Consumer End Use Survey Volume 1- Household Energy \& Transport, Kingston: The Planning Institute of Jamaica \& The Statistical Institute of Jamaica.

[2] Acar, C. \& Dincer, I., 2013. Comparative Assessment of Hydrogen Production Methods from Renewable and NonRenewable Sources. International Journal of Hydrogen Energy, p. 12.
[3] Barbir, F., 2005. PEM Electrolysis for Production of Hydrogen from Renewable Energy Sources. Solar Energy, 78(2005), pp. 661-669.

[4] Biddyut, P., 2009. Direct Coupling of the Photovoltaic Array and PEM Electrolyser in Solar Hydrogen Systems for Remote Area Power Supply. Melbourne: RMIT University.

[5] Bilgen, E., 2001. Solar Hydrogen for PhotovoltaicElectrolyser Systems. Energy Conversion and Management, Issue 42, pp. 1047-1057.

[6] Degiorgis, L., Santarelli, M. \& Cali, M., 2007. Hydrogen from Renewable Energy:A pilot plant for thermal production and mobility. Journal of Power Sources, p. 10

[7] IEA, 2006. Energy For Cooking in Developing Countries. [Online] Available at: http://www.iea.org/publications/freepublications/publica tion/cooking.pdf [Accessed November 2013].

[8] Johnson , E., 2012. Substituting LP Gas for Wood: Carbon and Deforestation Impacts, Zurich: World LP Gas Association.

[9] Lymperopoulos, N. \& Zoulias, E., 2008. Hydrogen-based Autonomous Power Systems: Techno-economic Analysis of the Integration of Hydrogen in Autonomous Power Systems. s.l.:Springer.

[10] Meteotest, 2014.Weather Stations in Meteonorm. [Online] Available http://meteonorm.com/en/ [Accessed July 2014].

[11] Nowotny, J. \& Veziroglou, N., 2011. Impact of Hydrogen on the Environment. International Journal of Hydrogen Energy, pp. 13218-13224.

[12] Proton Onsite, 2014. Proton Onsite. [Online] Available at: http://protononsite.com/ [Accessed May 2014].

[13] The University of Wisconsin, 2013. TRNSYS 17. [Online] Available at: http://sel.me.wisc.edu/trnsys/features/features.html [Accessed September 2014].

[14] TRNSYS 17, 2012. Mathematical Reference, Madison: Solar Energy Laboratory, University of Wisconsin.

[15] UN, 2006. Millennium Project. [Online] Available at:http://www.unmillenniumproject.org/goals/gti.htm\#go all [Accessed October 2014].

[16] Veziroglou, N. T. \& Sahin, S., 2008. 21st Century's Energy: Hydrogen Energy System. Energy Conversion and Management, 49(2008), pp. 1820-1831.

[17] World Health Organisation, 2006. Fuel For Life - Household Energy and Health. [Online] Availableat:

http://www.who.int/indoorair/publications/fuelforlife.pdf [Accessed October 2014].

[18] World Health Organisation, 2006. World Health Organisation. [Online] Available at: http://www.who.int/mediacentre/news/releases/2006/pr2 2/en/ [Accessed November 2013].

[19] Zini, G. \& Tartarini, P., 2012. Solar Hydrogen Energy Systems. Milano: Springer.

[20] Zoulias, E. \& Lymperopoulos, N., 2007. Technoeconomic Analysis of the Integration of Hydrogen Energy Technologies in Renewable Energy based Stand Alone Power Systems. Renewable Energy, Volume 32, pp. 680- 696. 